\title{
The Medical Home: Growing Evidence to Support a New Approach to Primary Care
}

\section{Thomas C. Rosenthal, MD}

Introduction: A medical home is a patient-centered, multifaceted source of personal primary health care. It is based on a relationship between the patient and physician, formed to improve the patient's health across a continuum of referrals and services. Primary care organizations, including the American Board of Family Medicine, have promoted the concept as an answer to government agencies seeking political solutions that make quality health care affordable and accessible to all Americans.

Methods: Standard literature databases, including PubMed, and Internet sites of numerous professional associations, government agencies, business groups, and private health organizations identified over 200 references, reports, and books evaluating the medical home and patient-centered primary care.

Findings: Evaluations of several patient-centered medical home models corroborate earlier findings of improved outcomes and satisfaction. The peer-reviewed literature documents improved quality, reduced errors, and increased satisfaction when patients identify with a primary care medical home. Patient autonomy and choice also contributes to satisfaction. Although industry has funded case management models demonstrating value superior to traditional fee-for-service reimbursement adoption of the medical home as a basis for medical care in the United States, delivery will require effort on the part of providers and incentives to support activities outside of the traditional face-to-face office visit.

Conclusions: Evidence from multiple settings and several countries supports the ability of medical homes to advance societal health. A combination of fee-for-service, case management fees, and quality outcome incentives effectively drive higher standards in patient experience and outcomes. Community/ provider boards may be required to safeguard the public interest. (J Am Board Fam Med 2008;21: 427-440.)

"The better the primary care, the greater the cost savings, the better the health outcomes, and the greater the reduction in bealth and health care disparities." 1

The term "medical home" was first coined by the American Academy of Pediatrics in $1967 .^{2}$ The American Academy of Family Physicians embraced the model in its 2004 Future of Family Medicine

This article was externally peer reviewed.

Submitted 31 December 2007; revised 18 May 2008; accepted 20 May 2008.

From the Department of Family Medicine, University of Buffalo, NY.

Funding: none.

Conflict of interest: none declared.

Corresponding author: Thomas C. Rosenthal, MD, Department of Family Medicine, University of Buffalo, 462 Grider Street, Buffalo, NY 14215 (E-mail: trosenth@acsu.buffalo.edu).

\footnotetext{
See Related Commentary on Page 370.
}

project $^{3}$ and the American College of Physicians issued a primary care medical home report in $2006 .{ }^{4}$ The concept of the medical home has recently received attention as a strategy to improve access to quality health care for more Americans at lower cost.

In the medical home, responsibility for care and care coordination resides with the patient's personal medical provider working with a health care team. ${ }^{5}$ Teams form and reform according to patient needs and include specialists, midlevel providers, nurses, social workers, care managers, dietitians, pharmacists, physical and occupational therapists, family, and community. ${ }^{4}$ Medical home models vary but their success depends on their ability to focus on the needs of a patient or family one case at a time, recruiting social services, specialty medical services, and patient capabilities to solve problems. ${ }^{6}$ In the United States primary care has been viewed largely as a discrete hierarchical 
level of care. Recently, however, business organizations taking a systems approach to problem solving typical of industry have endorsed the concept of a personal primary care physician as an efficient strategy for delivering a broad range of services to consumers on an as-needed basis. ${ }^{7,8}$ In its most mature form, a medical home may integrate medical and psychosocial services in a model more in concert with documented patient health beliefs. ${ }^{9-11}$

Most developed nations assure patient access to primary care physicians whose payments are, at least in part, based on guidelines and outcomes established by consumer/provider oversight. However, high utilization of technology and procedures in the United States have created the misperception that universal access to health care is too expensive, and some countries struggle to match Americans' access to procedures. ${ }^{12}$ Unfortunately, the reliance on high technology and procedures has exposed Americans to adverse events and errors possibly related to overuse. ${ }^{13,14}$

Although many Americans are not certain about what constitutes primary care, they want a primary care physician. ${ }^{15}$ They assume quality and appreciate technology but value relationship above all else. ${ }^{16,17}$ Racial and ethnic disparities are significantly reduced for families who can identify a primary care provider who facilitates access to a range of health providers. ${ }^{18}$ Urban and rural communities that have an adequate supply of primary care practitioners experience lower infant mortality, higher birth weights, and immunization rates at or above national standards despite social disparities. ${ }^{19-22}$ This article reviews both the peer-reviewed literature and program evaluations of medical homes to assist primary care providers and health planners in assessing the usefulness of the model in their own communities and practices.

\section{Methods}

The outline and subtitles for this article are from the 2006 Joint Principles of the Patient-Centered Medical Home issued by the American Academy of Family Physicians, the American College of Physicians, and the American Academy of Pediatrics. ${ }^{4}$ They have been used to facilitate the application of findings presented in this paper to policy development at the medical office and government levels.

PubMed was searched using "medical home" and "patient-centered care" as search phrases. The
Internet sites of the Commonwealth Fund, the Center for Health Care Strategies, the State of North Carolina, the National Health Service of the United Kingdom, and Web sites were searched. US Family Medicine Department Chairs were surveyed by e-mail in October 2007 to expand the list of medical home evaluation studies. The American Academy of Family Physicians' Graham Center supplied their growing bibliography on the medical home concept. These sources led to secondary searches of cited literature and reports. More than 200 publications and several books were reviewed by the author. Articles were selected for citation if they offered original research, meta-analyses, or evaluation of existing programs. The unique characteristics of programs and variations in methodologies made meta-analysis at this level inappropriate. An annotated bibliography of cited references was circulated to members of the New York State Primary Care Coalition, the New York State Health Department, and members of the Association of Departments of Family Medicine for response and reaction. Some key thought pieces are referenced to assist readers who may use this for policy development.

\section{Medical Home Principles}

Table 1 summarizes several principles of medical homes and the quality of the literature supporting the principle.

\section{Personal Physician}

Each patient has an ongoing relationship with a personal physician trained to provide first contact and continuous and comprehensive care. ${ }^{4}$

\section{Supporting Literature}

When people become sick, they use stories to describe their experience. Patient-oriented care is bound up in the physician's ability to accurately perceive the essence of a patient's story. ${ }^{31,32}$ Perception, or empathy, is enhanced by a doctorpatient relationship which, like any relationship, develops incrementally. ${ }^{33}$ Relationships do not replace technical expertise and patients accept that quality specialty care often means being cared for by providers with whom they have a limited relationship. ${ }^{34}$

In primary care, a longitudinal relationship is an important tool to enlighten a personalized applica- 


\begin{tabular}{|c|c|c|c|}
\hline Recommendation & $\begin{array}{l}\text { Evidence } \\
\text { Rating }\end{array}$ & References & Comments \\
\hline $\begin{array}{l}\text { Patients who have a continuity relationship } \\
\text { with a personal care physician have } \\
\text { better health process measures and } \\
\text { outcomes. }\end{array}$ & 1 & $23,34,41,47,52$ & $\begin{array}{l}\text { Continuity is most commonly associated } \\
\text { with primary care, but cancer care, } \\
\text { dialysis, and diabetes care are } \\
\text { examples of specialty continuity. }\end{array}$ \\
\hline $\begin{array}{l}\text { Multiple visits over time with the same } \\
\text { provider create renewed opportunities to } \\
\text { build management and teaching } \\
\text { strategies tailored to individual progress } \\
\text { and receptivity. }\end{array}$ & 2 & $24,25,38,39,46,49,54,55$ & $\begin{array}{l}\text { Neither primary care nor specialty care } \\
\text { can meet their full potential if } \\
\text { provided in a vacuum. All studies are } \\
\text { challenged to evaluate any piece of } \\
\text { the system in isolation from the } \\
\text { context of specialty or other } \\
\text { community services. }\end{array}$ \\
\hline $\begin{array}{l}\text { Minorities become as likely as non- } \\
\text { minorities to receive preventive } \\
\text { screening and have their chronic } \\
\text { conditions well managed in a medical } \\
\text { home model. }\end{array}$ & 2 & $19,20,22,26,27$ & $\begin{array}{l}\text { Rigorous program evaluations, } \\
\text { secondary population analyses, and } \\
\text { observational comparison studies } \\
\text { show consistent findings. }\end{array}$ \\
\hline $\begin{array}{l}\text { In primary care, patients present at most } \\
\text { visits with multiple problems. }\end{array}$ & 1 & $06,64,65$ & $\begin{array}{l}\text { The use of each office visit to care for } \\
\text { multiple problems is a property of } \\
\text { primary care. }\end{array}$ \\
\hline $\begin{array}{l}\text { Specialists generate more diagnostic } \\
\text { hypotheses within their domain than } \\
\text { outside and assign higher probabilities to } \\
\text { diagnoses within that domain. }\end{array}$ & 2 & 73,74 & $\begin{array}{l}\text { The interface between primary care and } \\
\text { specialty care needs further research. }\end{array}$ \\
\hline $\begin{array}{l}\text { The more attributes of the medical home } \\
\text { demonstrated by a primary care practice, } \\
\text { the more likely patients are to be up to } \\
\text { date on screening, immunizations, and } \\
\text { health habit counseling, and the less } \\
\text { likely they are to use emergency rooms. }\end{array}$ & 2 & $28,29,94,95,106,107,121$ & \\
\hline
\end{tabular}

1 = consistent, good quality evidence; 2 = limited quality, patient-oriented evidence; 3 = consensus, usual practice, expert opinion, or case series. ${ }^{30}$

tion of strategies that will achieve incremental improvements in health sustainable through the ever challenging events of life. ${ }^{35,36}$ Specialty care can often be judged by how well something is done to the patient. Primary care is often best judged by how well the patient changes behavior or complies with treatment, activities the patient must do themselves. This difference becomes blurred in areas of chronic kidney disease (nephrologist), cancer care (oncologist), and diabetic management (endocrinologist) because of the long-term management relationship with the patient.

A relationship over time between patient and generalist also modifies resource utilization. A survey of physicians in Colorado by Fryer et $\mathrm{al}^{37} \mathrm{dem}$ onstrated that in communities with high numbers of specialists or low numbers of generalists, specialists may spend $27 \%$ of patient contact time performing primary care services. Just as with anyone practicing outside of their area of comfort, this inevitability should raise concerns. Chart reviews of over 20,000 outpatient encounters by Greenfield ${ }^{38}$ and 5,000 inpatient encounters by Weingarten ${ }^{39}$ demonstrated that specialists practicing outside of their area of expertise order more tests and make more referrals than generalists.

Americans spend less time with a primary care physician than patients in countries with better health outcomes. ${ }^{40}$ Yet, community-level studies indicate that availability of primary care lowers mortality. ${ }^{41}$ The influence of primary care is second to socioeconomic conditions in lowering the frequency of strokes and cancer deaths. ${ }^{42-45}$ In a study of 11 conditions, Starfield et $\mathrm{al}^{46}$ found that patients had more monitoring of more parameters for all their conditions if they received care within a continuous primary care physician relationship as opposed to disease-specific specialty care.

Quality care is not solely dependent on insurance coverage. An analysis of administrative data in a Midwestern Canadian city with universal coverage documented that patients who had a continuous relationship with a personal care provider were more likely to receive cancer screening, had higher 
vaccination rates, and had lower emergency department use. ${ }^{47}$ In a critical review of the literature on continuity, Saultz and Lochner ${ }^{34}$ analyzed 40 studies tracking 81 care outcomes, 41 of which were significantly improved by continuity. Of the 41 cost variables studied, expenditures were significantly lower for 35. Saultz and Lochner ${ }^{34}$ concluded that the published literature could not reveal if patient satisfaction with a provider lead to continuity or if continuity lead to satisfaction, but findings were generally consistent with a positive impact on measured outcomes.

A Norwegian study determined that 4 visits with a provider were necessary for accumulated knowledge to impact use of laboratory tests, expectant management, prescriptions, and referrals. ${ }^{48}$ Each visit in a continuous relationship renews an opportunity to build management and teaching strategies tailored to individual progress, receptivity, and capacity for compliance and change across the multiple medical conditions faced by many patients. ${ }^{48}$ Gulbrandsen et al's ${ }^{50}$ review of visits by 1401 adults attending 89 generalists demonstrated that continuity of care increased the likelihood that the provider was aware of psychosocial problems impacting health. Others ${ }^{51-53}$ studied the impact of a primary care "gatekeeping" model's impact on Medicaid health management organization patients in Missouri and showed an increase of visits to primary care and fewer visits to emergency rooms, specialists, and nonphysician providers. Continuity has generally been shown to achieve quality at a lower cost. ${ }^{54,55}$ In a qualitative analysis, Bayliss et $\mathrm{al}^{56}$ concluded that patients with multiple comorbidities experienced barriers to self care, such as medication problems, chronic disease interactions, and adverse social and emotional environments requiring coordination of strategies across the comorbidities. Patients attribute health care errors to the breakdown of the doctor-patient relationship $70 \%$ of the time. ${ }^{57}$

\section{Team-directed Medical Practice}

A personal medical provider, usually a physician, leads a team of caregivers who take collective responsibility for ongoing patient care.

\section{Supporting Literature}

Eighty-seven percent of primary care physicians think an interdisciplinary team improves quality of care. ${ }^{58}$ Separate studies of primary care offices in upstate New York and California, identified by their positive community reputation, found that all used a coordinated team model regardless of structure (private practice, community health center, hospital-owned). The practices either directly provided or coordinated a spectrum of services including social/behavioral services, rehabilitation, and coordinated specialty care. ${ }^{10,59}$

A team expands on the inherent limits in a $15-$ minute office visit during which demands for preventive care, chronic disease management, and new complaints compete. ${ }^{60}$ Team care increases the contact points between patient and health care team and decreases the likelihood that acute complaints will distract providers from making appropriate adjustments in the care of chronic conditions.

Comprehensive patient management implies more than office visits. In one model a medical assistant measures vital signs and takes an interim history in the examination room then remains with the patient during the physician encounter and stays behind for a debriefing with the patient after the visit. The same assistant contacts the patient after the visit and before the next visit. ${ }^{61}$ Phelan et $\mathrm{al}^{63}$ found that a interdisciplinary geriatric team model screened for more syndromes and improved care at 12 months, although there was little significant improvement thereafter. Disease-specific team models produce good results for the focal disease but are less successful with comorbidities. ${ }^{45}$ Multidisciplinary team care of disabled adults in sheltered housing shifted expenditures from unproductive repeat hospitalizations to personal care and increased outpatient visits. ${ }^{63}$

\section{Whole-Person Orientation}

The personal physician or provider maintains responsibility for providing for all of the patient's health care needs and arranges care with other qualified professionals as needed. This includes care for all stages of life: acute care, chronic care, preventive services, and end-of-life care. ${ }^{4}$

\section{Supporting Literature}

Family physicians manage 3.05 problems per patient encounter. They chart 2.82 problems and bill for 1.97. Ninety percent of patients have at least 2 concerns. ${ }^{64}$ Patients over the age of 65 average 3.88 problems per visit and diabetics average 4.6. ${ }^{65}$ In a study of 211 patient encounters, Parchman et al ${ }^{66}$ 
found that the number of complaints raised by patients tended to decrease the likelihood that a diabetic would have an adjustment made to a needed medication. Providers compensated by shortening the time to next visit by an average of 8.6 days.

By way of illustration, headache is often a secondary complaint in primary care. Only $3 \%$ of patients seen in a primary care office with a headache will have a computed tomography scan, and of these only $5 \%$ will have significant findings. ${ }^{67}$ If the history and physical fail to raise suspicion of an intracranial process, headache patients are often treated according to symptoms and encouraged to return if symptoms do not resolve as expected while still receiving care for the primary chronic condition. Tactical options include follow-up contact by a member of the health team or earlier recheck.

The recheck plan for nonurgent conditions is a critical element of primary care. Continuity in the relationship establishes the mutual confidence needed for a watchful waiting or recheck strategy. ${ }^{68}$ Whereas an immediate diagnostic work-up may quickly arrive at a specific diagnosis, a measured wait and see approach in the absence of "red flags" often confirms the initial impression. "Wait and see" has become a legitimate focus of research in otitis media and some pain syndromes. ${ }^{69,70}$

\section{Care Is Coordinated and/or Integrated Across All Domains of the Health Care System}

Modern health care presents several effective strategies for any single complaint, creating important options for diagnosis and treatment but also increasing the potential for overuse and confusion. ${ }^{4}$

\section{Supporting Literature}

The integration of primary care as an overarching approach to population health management is perhaps best elucidated by a discussion of care integration in a robust modern health care system. Medical homes should not function as entry-level care providers but rather as strategic access managers.

Back pain is a frequent primary care complaint. Patients with "red flag" orthopedic or neurologic complications need to be identified and urgently referred for specialty care. Most will require supportive care including pain relief, exercise, stretching, and physical therapy. A minority of patients who fail to respond still need help selecting a sur- geon or a rehabilitation program and need guided readjustment to their workplace. ${ }^{8}$ Fears and misunderstandings are the greatest threat to recovery but receiving an magnetic resonance imaging scan early in the course of back pain is more strongly associated with eventual surgery than are clinical findings. ${ }^{71}$ The challenge is to meet the patient's need for management and order additional tests at the precise point in the course of illness to be productive.

The skills associated with specialty care must be learned in centers that see preselected patients with a high likelihood of needing specialty procedures. An intense experience essential for training predisposes toward overestimation of the likelihood of severe or unusual conditions in the general population and contributes to an overuse of diagnostic and therapeutic modalities. ${ }^{72-74}$ Care across the continuum is more than access to procedures.

When generalist physicians are less available than specialists, specialists often refer secondary problems to other specialists. For example, after a myocardial infarction a patient may be referred by the cardiologist to an endocrinologist, pulmonologist, and a rheumatologist to manage the patient's long-standing diabetes, cardiac obstructive pulmonary disorder, and osteoarthritis. Specialists who feel unsupported by primary care services schedule more follow-up appointments, many of which duplicate services provided by the primary care physician. ${ }^{73,75}$

However, even in universal coverage societies like the United Kingdom, patients report greater satisfaction when they are able to access specialty care directly. ${ }^{76}$ The lesson here is that medical homes should not become barriers to specialty access. The personal care team should facilitate referral to the most appropriate specialist at the appropriate time, consistent with patient concerns.

There is evidence to suggest that primary care involvement in a referral to another physician may improve quality. Children with tonsillitis who are referred by primary care physicians to surgeons have fewer postoperative complications than do children whose parents bypassed the primary care provider. ${ }^{77}$ At Kaiser Permanente, primary care physician-facilitated referrals have lower hospitalization rates than do self referrals. ${ }^{78}$ Primary care physicians who care for their hospitalized patients provide care that is as efficient as that provided by hospitalists. $^{76}$ 
Mental health coordination is no different. Smith et $\mathrm{al}^{80}$ reviewed the literature on management of patients with unexplained symptoms and psychosocial distress, concluding that $80 \%$ of these patients accept management by primary care physicians but only $10 \%$ will attend a psychosocial referral. When a referral is made, the primary care physician plays an important role in outcome success. ${ }^{81}$ Full integration of primary medical care with mental health care improves outcomes in both arenas. $^{82-84}$

\section{Quality and Safety}

Clinical excellence is enhanced by integration of information technology into medical practice and tracking of quality measures. ${ }^{4}$

- Evidence-based medicine and clinical decision support tools should be incorporated into practice.

\section{Supporting Literature}

One challenge to medical home evaluation will be establishing outcome measures that truly affect patient wellness. Specialists are good at adhering to guidelines within their field of expertise. ${ }^{85-87}$ However, Hartz and James ${ }^{88}$ reviewed 42 published articles comparing cardiologist to generalist care of myocardial infarctions and found that none of the studies took into account patient preferences, severity of comorbid disease, general health status, or resource availability. Confounding comorbidities, physical or behavioral, frequently exclude patients from the clinical trials that generate disease specific guidelines. $^{89,90}$

Yet when primary care group practices systematically organize themselves to meet guideline standards they achieve equivalent outcomes. ${ }^{91-93}$ It is a challenge to primary care that generalists perform better at meeting patient-centered guidelines such as exercise, diet, breastfeeding, smoking cessation, and the use of seat belts and less well at meeting disease-specific guidelines. However, patients who report having a continuous relationship with a personal care provider are very likely to receive evidence-based care. ${ }^{94,95}$

- Physicians will accept accountability for continuous quality improvement through voluntary engagement in performance measurement.
Supporting Literature

Public reporting of health care measures encourages physicians to meet benchmarks. The conundrum is that reporting variations does little to $e x-$ plain variations. ${ }^{96}$ Fifty-five percent of generalists agree that patients should have access to performance data although there is little consensus yet on parameters. ${ }^{58}$ Whereas the Healthplan Employer Data Information Set has more than 60 different measures (including immunizations, women's health, maternity care, behavioral health, and asthma), accuracy has been limited because the data are based on billing records. Efforts to collect data directly from the patient's primary care record have been piloted by the Wisconsin Collaboration for Health Care Quality but the lack of standard interoperability of records is challenging. ${ }^{97}$

Because continuity is central to patient satisfaction with, and the function of, a medical home, quality should be trended over time and include aspects of care that reflects functions of the whole team. ${ }^{98}$ One model incorporates all office personnel (assistants, nurses, and providers) in interviews that identify perceived challenges to quality. Together the office staff and physicians rank priorities, brainstorm solutions, implement action, and monitor results. ${ }^{99}$ The science of quality measurement in primary care is evolving and more research is needed. However, waiting for perfect measures should not delay implementation of good measures.

- Patients actively participate in decision making, including seeking feedback to ensure that patients' expectations are being met.

\section{Supporting Literature}

Only $36 \%$ of generalists and $20 \%$ of specialists survey their patients. ${ }^{58}$ A recent survey of all primary care and ambulatory specialty physicians in Florida showed only modest advances in the adoption of e-mail communication, and little adherence to recognized guidelines for e-mail correspondence. ${ }^{100}$ A study of 200 patients with rheumatoid arthritis who initiated their own follow-up found patients were significantly more confident and satisfied with their care and used fewer specialty services, including fewer hospitalizations, and saw their primary care physician as frequently as a matched control group for whom specialty care was more limited. ${ }^{76}$ These findings again suggest that 
the primary care physician's role as a gate opener and advisor may be more efficient than as a gatekeeper. Such a role requires effective communication.

- Information technology has potential to support optimal patient care, performance measurement, patient education, and communication.

\section{Supporting Literature}

Primary care is at a tipping point for implementation of electronic medical records. Twenty-three percent of practices currently use electronic medical records; another $23 \%$ would like to implement electronic records within the next year. ${ }^{58}$ Electronic records have not yet automated collection of consultant reports and test results for patient visits. Eventually a system of health information management will network electronic records in offices, hospitals, and ancillary care centers within a wellprotected national grid capable of managing huge amounts of data. ${ }^{101}$

A qualitative study of family medicine practices suggests that approximately a year after implementation, practices with electronic records initiate but struggle with effective tracking of clinical outcomes data. ${ }^{102}$ At 5 years, practices with electronic records document more frequent testing of glycosylated hemoglobins and lipid levels but do not achieve better control. ${ }^{103}$ High quality primary care groups find having an electronic medical record a useful tool but not essential to meeting guidelines. ${ }^{104}$

- Practices go through a voluntary recognition process by an appropriate nongovernmental entity to demonstrate that they have the capabilities to provide patient centered services consistent with the medical home model.

Successful implementation of the medical home model will necessitate recruitment of early adopting, high-performing practices that wish to be measured against benchmarks. During this period measures that lead to improved patient management can be identified and actual costs of care and savings demonstrated. Realistically, it will take years to roll out an evolution in health care of this magnitude and early innovators may be more highly motivated and successful than later implementers. ${ }^{105}$
- Enhanced access to care through systems such as open scheduling, expanded hours, and new options for communication between patients, their personal physician, and office staff.

Medical homes should be challenged to assure that patients have access to the right care at the right time in the right place, including the right specialty care. Many of these strategies are focused on viewing services from the patient's perspective, including extended hours and open access. ${ }^{106-108}$

E-mail or Internet-based communication promises to increase patient/physician interaction and interfere less with the patient's work schedule. To be embraced in health care, electronic communication will need to be reimbursed. Kaiser Permanente of Colorado is paying $95 \%$ of the CPT 99213 office visit fee for virtual office visits. ${ }^{109}$ Internet-based portals are also available to provide secure communication. ${ }^{110}$

\section{Demonstration Projects}

Reorganization of primary health care in the United States may be reaching its own tipping point. In 2007 the UnitedHealth Group in Florida, CIGNA, Humana, Wellpoint, and Aetna began supporting primary care practices willing to incorporate quality improvement and active patient management in medical home systems. ${ }^{111}$ North Carolina's Medicaid managed care program, North Carolina Community Care, offers a per-member/ per-month management fee to physician networks that use evidence-based guidelines for at least 3 conditions, track patients, and report on performance. ${ }^{112}$ By 2005 primary care practices realized $\$ 11$ million in enhanced fees but generated savings of \$231 million. ${ }^{113}$ Erie County, NY, implemented a primary care partial capitation program in 1990 for Medicaid/Medicare patients with chronic disabilities, including substance abuse. A per-member/ per-month management fee improved quality of care, decreased duplication, lowered hospitalization rates, and improved patient satisfaction while saving \$1 million for every 1000 enrollees. ${ }^{114}$ The Veterans Affairs Administration integrated information technology with a primary care-based delivery system for qualified Veterans and improved quality of care. It now costs $\$ 6,000$ less per year to care for a veteran over the age of 65 than for a Medicare recipient. ${ }^{115}$ 
The Netherlands offers physicians incentives for efficiency, outcomes, and quality in a universal coverage model originally proposed for the United States. ${ }^{116}$ Everyone must purchase basic community-rated health insurance through private insurers. The plan has improved compensation for primary care services and has improved distribution of services into previously underserved communities. ${ }^{117,118}$

In 2001, the United Kingdom's National Health Service contracted with general practitioners to provide medical home services to patients. By 2005 these contracts had improved quality of care. ${ }^{119}$ The rate of improvement further accelerated when financial incentives were added in 2005. ${ }^{105,120}$

\section{Limitations of This Review}

Primary care practices are very complex. Each practice has a philosophy, style, and culture within which physicians and staff deliver patient care. ${ }^{121}$ Any review of the medical home should be balanced by a concern that many practices already feel burdened by existing work demands and perceive little capacity to accept new responsibilities in patient care. Measuring outcomes further adds to the workload and may not be successful in unmotivated practices. ${ }^{122}$ It is possible that placing additional responsibilities on a primary care visit may actually interfere with secondary detection of conditions such as skin cancers or depression. ${ }^{123-125}$

Finally, there are limitations in the methods used in this review. The quality of each study was subjectively determined and could not be analyzed in the aggregate because most studies and evaluations used different interventions and approaches to data collection. Studies often reflect unique characteristics of providers and patients in incomparable settings. Generalizations are possible only in light of the consistency of the conclusions drawn by a large body of work.

\section{Reimbursing the Medical Home}

Institutionalizing the medical home as the foundational approach to health delivery strategy in the United States will require a reformulation of reimbursement policy. Overall, the average salary of American physicians is 7 times greater than that of the average American worker. Primary care physicians in the United States earn 3 times the average worker's income. In most of the industrialized world the overall physician-to-average worker income ratio is 3:1. ${ }^{126}$ The Centers for Medicare and Medicaid Services' (CMS) Resource-Based Relative Value Scale, designed in 1992 to reduce inequality between fees for primary care and payment for procedures, has failed. As structured, the committee that advises CMS has 30 members, 23 of whom are appointed by medical specialty societies. ${ }^{127}$ This group has tended to approve procedural services resulting in increased revenues for procedural specialties. ${ }^{128}$ Between 2000 and 2004, primary care income increased $9.9 \%$ whereas specialty incomes rose $15.8 \% .^{129}$ A 2007 effort to increase primary care reimbursement improved payments by $5 \%$, not the $37 \%$ projected by Medicare. ${ }^{130}$

Compounding these salary discrepancies, $40 \%$ of the primary care work load (arranging referrals, completing forms, communicating with patients, emotional support, and encouragement) is not reimbursed by a face-to-face fee-for-service methodology. ${ }^{131}$ A sophisticated payment system would support team care, health information technology, quality improvement, e-mail and telephone consultation, and be adjusted by case mix. ${ }^{132}$

\section{Where Will the Money Come From?}

The need for change in the reimbursement structure has even reached the popular press. Consumer Reports blames reimbursement policies for the overuse of 10 common procedures, concluding that the US payment system discourages counseling, care coordination, and evidence-based assessment. ${ }^{133}$ A primary care-based system may cost $30 \%$ less ${ }^{134}$ because patients experience fewer hospitalizations, less duplication, and more appropriate use of technology. ${ }^{75,135}$ Case-adjusted rates of hospitalizations for heart disease and diabetes are 90\% higher for cardiologists and 50\% higher for endocrinologists than for primary care physicians. ${ }^{38,136}$ Even acute illnesses, such as community-acquired pneumonia, cost less for equivalent outcomes when managed by a primary care physician. ${ }^{137}$

Federally funded Community health centers form the largest network of primary care medical homes in the United States. In 2005 the average cost of caring for a patient in a community health center was $\$ 2,569$ compared with $\$ 4,379$ for the general population. ${ }^{138}$

Variations in expenditures from one community to another also suggest opportunities for reducing 
expenditures while preserving quality. New York State and California spend over $\$ 38,000$ per Medicare recipient in the last 2 years of life compared with Missouri, New Hampshire, and North Carolina, where expenditures are below $\$ 26,000 .{ }^{139}$ If half of the expenditure variation could be captured, there would be adequate resources to provide uninsured Americans with a personal physician in a patient-centered medical home. ${ }^{134 z r e f x}$

Improved quality will also cut expenditures. An analysis by Bridges to Excellence estimated that maintaining the glycohemoglobin at 7 in a diabetic patient saves \$279 a year in health costs per patient. Keeping a diabetic's low-density lipoprotein below 100 saves \$369 per year, and keeping the blood pressure below 130/80 saves \$494. Keeping all measures at target saves $\$ 1,059$ per patient per year. $^{140}$

\section{Reimbursement Models}

Medical practices are business entities. Rewards for change must exceed the cost of change. ${ }^{141,142} \mathrm{~A}$ 3-component fee schedule considered by the American Academy of Family Physicians, the American Academy of Pediatrics, and the American College of Physicians would consist of (1) a fee for service (per visit); (2) a monthly management fee for practices contracting to provide medical home services; and (3) an additional bonus for reporting on quality performance goals. ${ }^{143,144}$

Maintaining fee-for-service reimbursement supports provision of essential face-to-face services. However fee-for-service reimbursement should be broadened to embrace e-mail or Web-based virtual office visits, perhaps pegging them to some proportion of a routine office visit. ${ }^{109}$

A per-member/per-month management fee for Medicaid patients with or without chronic disease was enough to trigger case management and quality reporting in the North Carolina Medicaid program. ${ }^{12}$ In one upstate New York county the enhanced management fee for patients with both mental and physical health problems approximates $\$ 10$ per member/per month. ${ }^{114}$ Other models have paid fractional fees for specific activities such as chronic disease registries, guideline implementation, and outcomes tracking. A capitation of $\$ 5.50$ per member/per month (\$66 per year) is roughly half of the $\$ 110$ per year savings projected by the Bridges to Excellence project for well persons enrolled in a medical home. ${ }^{140}$ The fee would be expected to support physician management time, outcomes reporting, electronic record maintenance cost, and a full-time professionally trained case manager. Enhanced services include patient education, telephonic case management, and improved patient access.

The quality incentive is a pay-for-performance fee that recognizes achievement of standards of care. HMOs have traditionally relied on claims data for tracking billed procedures. The patient record is more accurate but will require new resources to harvest. ${ }^{145}$ When paid at 3-month intervals, quality incentives are frequent enough to trigger continuous improvement efforts but spaced sufficiently to reflect impact of changes. Observation studies have confirmed that practices add staff, install electronic records, and network with community agencies to be eligible for incentives. ${ }^{105,144}$ To be effective, criteria must be measurable, based on evidence, and amenable to medical management. Both the measures and incentives must be chosen and incentivized with care to assure providers do not simply deselect complex patients, for it is the complex patients who have the most to gain in a medical home environment. ${ }^{146}$ Eventually, public reporting of physician data will facilitate greater patient participation and trust. ${ }^{147}$ Studies for as long as 6 years show that appropriately selected incentives can maintain physician satisfaction, patient satisfaction, and long-term performance. ${ }^{148}$ Incentives also reinforce the office team structure. ${ }^{149}$

Oversight is essential to the ultimate success of a patient centered medical home system of care. The United Kingdom established the National Institute for Health and Clinical Excellence to manage incentives and define objectives of their health system. Using full-time investigators, National Institute for Health and Clinical Excellence publishes and updates clinical appraisals on efficacy. Oversight of National Institute for Health and Clinical Excellence is provided by a board of health professionals, patients, and employers. ${ }^{150}$

\section{References}

1. Epstein AJ. The role of public clinics in preventable hospitalizations among vulnerable populations. Health Serv Res 2001;36:405-20.

2. Sia C, Tonniges TF, Osterhus E, Taba S. History of the medical home concept. Pediatrics 2004;113(5 Suppl):1473-8.

3. Future of Family Medicine Project Leadership 
Committee. The Future of Family Medicine: a collaborative project of the family medicine community. Ann Fam Med 2004;2(Suppl 1):S3-32.

4. Barr M. The advanced medical home: a patientcentered, physician-guided model of health care. Philadelphia (PA): American College of Physicians; 2006.

5. Grumbach K, Bodenheimer T. A primary care home for Americans: putting the house in order. JAMA 2002;288:889-93.

6. Lantz PM, Lichtenstein RL, Pollack HA. Health policy approaches to population health: the limits of medicalization. Health Aff (Millwood) 2007; 26:1253-7.

7. Finch RA. An employer's guide to behavioral health services: a roadmap and recommendations for evaluating, designing, and implementing behavioral health services. Washington, DC: National Business Group on Health; 2005.

8. Enthoven AC, Crosson FJ, Shortell SM. 'Redefining health care': medical homes or archipelagos to navigate? Health Aff (Millwood) 2007;26:1366-72.

9. Engel GL. The need for a new medical model: a challenge for biomedicine. Science 1977;196:12936.

10. Rosenthal T, Campbell-Heider N. The rural health care team. In: Geyman JP NT, Hart G, eds. Textbook of rural health care. New York: Mcgraw-Hill; 2001.

11. Bodenheimer T, Lorig K, Holman H, Grumbach $\mathrm{K}$. Patient self-management of chronic disease in primary care. JAMA 2002; 288:2469-75.

12. Royal College of General Practitioners. The future direction of general practice: a roadmap. London, UK: Royal College of General Practitioners; 2007.

13. Schoen C, Osborn R, Huynh PT, et al. Primary care and health system performance: adults' experiences in five countries. Health Aff (Millwood) 2004;(Suppl Web Exclusives):W4-487-503.

14. Woolf SH, Johnson RE. The break-even point: when medical advances are less important than improving the fidelity with which they are delivered. Ann Fam Med 2005;3:545-52.

15. Green LA, Graham R, Bagley B, et al. Task Force 1. Report of the Task Force on patient expectations, core values reintegration, and the new model of family medicine. Ann Fam Med 2004;2(Supp 1):S33-S50.

16. Main DS, Tressler C, Staudenmaier A, Nearing KA, Westfall JM, Silverstein M. Patient perspectives on the doctor of the future. Fam Med 2002; 34:251-7.

17. Coulter A. What do patients and the public want from primary care? BMJ 2005;331:1199-201.

18. Beal AC, Doty MM, Henandez SE, Shea KK, Davis $\mathrm{K}$. Closing the divide: how medical homes promote equity in health care. Results from the Common- wealth Fund 2006 Health Care Quality Survey. New York, NY June 20072006.

19. Parchman ML, Culler S. Primary care physicians and avoidable hospitalizations. J Fam Pract 1994; 39:123-8.

20. Gadomski A, Jenkins P, Nichols M. Impact of a Medicaid primary care provider and preventive care on pediatric hospitalization. Pediatrics 1998;101: E1.

21. Shi L, Macinko J, Starfield B, et al. Primary care, infant mortality, and low birth weight in the states of the USA. J Epidemiol Community Health 2004; 58:374-80.

22. Shi L, Macinko J, Starfield B, Politzer R, Wulu J, $\mathrm{Xu}$ J. Primary care, social inequalities, and allcause, heart disease, and cancer mortality in US counties, 1990. Am J Public Health 2005;95:67480.

23. Berry LL, Parish JT, Janakiraman R, et al. Patients' commitment to their primary physician and why it matters. Ann Fam Med 2008;6:6-13.

24. Moscovice I, Rosenblatt R. Quality-of-care challenges for rural health. J Rural Health 2000;16: $168-76$.

25. Moore LG. Escaping the tyranny of the urgent by delivering planned care. Fam Pract Manag 2006;13: 37-40.

26. Shi L, Macinko J, Starfield B, Politzer R, Wulu J, $\mathrm{Xu}$ J. Primary care, social inequalities and all-cause, heart disease and cancer mortality in US counties: a comparison between urban and non-urban areas. Public Health 2005;119:699-710.

27. Fiscella K, Holt K. Impact of primary care patient visits on racial and ethnic disparities in preventive care in the United States. J Am Board Fam Med 2007;20:587-97.

28. Flocke SA, Stange KC, Zyzanski SJ. The association of attributes of primary care with the delivery of clinical preventive services. Med Care 1998;36(8 Suppl):AS21-30.

29. Ryan S, Riley A, Kang M, Starfield B. The effects of regular source of care and health need on medical care use among rural adolescents. Arch Pediatr Adolesc Med 2001;155:184-90.

30. Ebell MH, Siwek J, Weiss BD, et al. Strength of Recommendation Taxonomy (SORT): a patientcentered approach to grading evidence in the medical literature. J Am Board Fam Pract 2004;17:5967.

31. Brody H. Edmund D. Pellegrino's philosophy of family practice. Theor Med 1997;18:7-20.

32. Groopman J. How doctors think. New York (NY): Houghton Mifflin Co.; 2007.

33. Pink DH. A whole new mind: why right-brainers will rule the future. New York (NY): Riverhead Books; 2006.

34. Saultz JW, Lochner J. Interpersonal continuity of 
care and care outcomes: a critical review. Ann Fam Med 2005;3:159-66.

35. Charon R. Narrative medicine: a model for empathy, reflection, profession and trust. JAMA 2001; 286:1897-902.

36. Halpern J. From detached concern to empathy: humanizing medical practice. London: Oxford University Press; 2001.

37. Fryer GE, Jr., Consoli R, Miyoshi TJ, Dovey SM, Phillips RL Jr, Green LA. Specialist physicians providing primary care services in Colorado. $\mathrm{J}$ Am Board Fam Pract 2004;17:81-90.

38. Greenfield S, Nelson EC, Zubkoff M, et al. Variations in resource utilization among medical specialties and systems of care. Results from the medical outcomes study. JAMA 1992;267:1624-30.

39. Weingarten SR, Lloyd L, Chiou CF, Braunstein GD. Do subspecialists working outside of their specialty provide less efficient and lower-quality care to hospitalized patients than do primary care physicians? Arch Intern Med 2002;162:527-32.

40. Bindman AB, Forrest CB, Britt H, Crampton P, Majeed A. Diagnostic scope of and exposure to primary care physicians in Australia, New Zealand, and the United States: cross sectional analysis of results from three national surveys. BMJ 2007;334: 1261.

41. Shi L. The relationship between primary care and life chances. J Health Care Poor Underserved 1992; 3:321-35.

42. Vogel RL, Ackermann RJ. Is primary care physician supply correlated with health outcomes? Int J Health Serv 1998;28:183-96.

43. Campbell RJ, Ramirez AM, Perez K, Roetzheim RG. Cervical cancer rates and the supply of primary care physicians in Florida. Fam Med 2003;35:60-4.

44. Shi L, Macinko J, Starfield B, Xu J, Politzer R. Primary care, income inequality, and stroke mortality in the United States: a longitudinal analysis, 1985-1995. Stroke 2003;34:1958-64.

45. Starfield B, Shi L, Macinko J. Contribution of primary care to health systems and health. Milbank Q 2005;83:457-502.

46. Starfield B, Lemke KW, Bernhardt T, Foldes SS, Forrest CB, Weiner JP. Comorbidity: implications for the importance of primary care in 'case' management. Ann Fam Med 2003;1:8-14.

47. Menec VH, Sirski M, Attawar D. Does continuity of care matter in a universally insured population? Health Serv Res 2005;40:389-400.

48. Hjortdahl P, Borchgrevink CF. Continuity of care: influence of general practitioners' knowledge about their patients on use of resources in consultations. BMJ 1991;303:1181-4.

49. Higashi T, Wenger NS, Adams JL, et al. Relationship between number of medical conditions and quality of care. N Engl J Med 2007;356:2496-504.

50. Gulbrandsen P, Hjortdahl P, Fugelli P. General practitioners' knowledge of their patients' psychosocial problems: multipractice questionnaire survey. BMJ 1997;314:1014-8.

51. Hurley RE, Paul JE, Freund DA. Going into gatekeeping: an empirical assessment. QRB Qual Rev Bull 1989;15:306-14.

52. O'Malley AS, Forrest CB. Continuity of care and delivery of ambulatory services to children in community health clinics. J Community Health 1996; 21:159-73.

53. Richman IB, Clark S, Sullivan AF, Camargo CA Jr. National study of the relation of primary care shortages to emergency department utilization. Acad Emerg Med 2007;14:279-82.

54. Raddish M, Horn SD, Sharkey PD. Continuity of care: is it cost effective? Am J Manag Care 1999;5: 727-34.

55. De Maeseneer JM, De Prins L, Gosset C, Heyerick J. Provider continuity in family medicine: does it make a difference for total health care costs? Ann Fam Med 2003;1:144-8.

56. Bayliss EA, Steiner JF, Fernald DH, Crane LA, Main DS. Descriptions of barriers to self-care by persons with comorbid chronic diseases. Ann Fam Med 2003;1:15-21.

57. Kuzel AJ, Woolf SH, Gilchrist VJ, et al. Patient reports of preventable problems and harms in primary health care. Ann Fam Med 2004;2:333-40.

58. Audet AM, Davis K, Schoenbaum SC. Adoption of patient-centered care practices by physicians: results from a national survey. Arch Intern Med 2006; 166:754-9.

59. Feifer C, Nemeth L, Nietert PJ, et al. Different paths to high-quality care: three archetypes of topperforming practice sites. Ann Fam Med 2007;5: 233-41.

60. Jaen CR, Stange KC, Nutting PA. Competing demands of primary care: a model for the delivery of clinical preventive services. J Fam Pract 1994;38: 166-71.

61. Bodenheimer T, Laing BY. The teamlet model of primary care. Ann Fam Med 2007;5:457-61.

62. Phelan EA, Balderson B, Levine M, et al. Delivering effective primary care to older adults: a randomized, controlled trial of the senior resource team at group health cooperative. J Am Geriatr Soc 2007; 55:1748-56.

63. Yaggy SD, Michener JL, Yaggy D, et al. Just for us: an academic medical center-community partnership to maintain the health of a frail low-income senior population. Gerontologist 2006;46:271-6.

64. Fortin M, Bravo G, Hudon C, Vanasse A, Lapointe L. Prevalence of multimorbidity among adults seen in family practice. Ann Fam Med 2005;3:223-8.

65. Beasley JW, Hankey TH, Erickson R, et al. How many problems do family physicians manage at each encounter? A WReN study. Ann Fam Med 2004;2:405-10. 
66. Parchman ML, Pugh JA, Romero RL, Bowers KW. Competing demands or clinical inertia: the case of elevated glycosylated hemoglobin. Ann Fam Med 2007;5:196-201.

67. Becker LA, Green LA, Beaufait D, Kirk J, Froom J, Freeman WL. Use of CT scans for the investigation of headache: a report from ASPN, Part 1. J Fam Pract 1993;37:129-34.

68. Rosenthal TC, Riemenschneider TA, Feather J. Preserving the patient referral process in the managed care environment. Am J Med 1996;100:33843.

69. Spiro DM, Tay KY, Arnold DH, Dziura JD, Baker MD, Shapiro ED. Wait-and-see prescription for the treatment of acute otitis media: a randomized controlled trial. JAMA 2006;296:1235-41.

70. Calnan M, Wainwright D, O’Neill C, Winterbottom A, Watkins C. Making sense of aches and pains. Fam Pract 2006;23:91-105.

71. Jarvik JG, Hollingworth W, Martin B, et al. Rapid magnetic resonance imaging vs radiographs for patients with low back pain: a randomized controlled trial. JAMA 2003;289:2810-8.

72. Mathers N, Hodgkin P. The gatekeeper and the wizard: a fairy tale. BMJ 1989;298:172-4.

73. Franks P, Clancy CM, Nutting PA. Gatekeeping revisited-protecting patients from overtreatment. N Engl J Med 1992;327:424-9.

74. Hashem A, Chi MT, Friedman CP. Medical errors as a result of specialization. J Biomed Inform 2003; 36:61-9.

75. Franks P, Fiscella K. Primary care physicians and specialists as personal physicians. Health care expenditures and mortality experience. J Fam Pract 1998;47:105-9.

76. Hewlett S, Kirwan J, Pollock J, et al. Patient initiated outpatient follow up in rheumatoid arthritis: six year randomised controlled trial. BMJ 2005;330: 171.

77. Roos NP. Who should do the surgery? Tonsillectomy-adenoidectiomy in one Canadian Province. Inquiry 1979;16:73-83.

78. Feachem RG, Sekhri NK, White KL. Getting more for their dollar: a comparison of the NHS with California's Kaiser Permanente. BMJ 2002; 324:135-41.

79. Lindenauer PK, Rothberg MB, Pekow PS, Kenwood C, Benjamin EM, Auerbach AD. Outcomes of care by hospitalists, general internists, and family physicians. N Engl J Med 2007;357:2589-600.

80. Smith RC, Lein C, Collins C, et al. Treating patients with medically unexplained symptoms in primary care. J Gen Intern Med 2003;18:478-89.

81. Rosenthal TC, Shiffner JM, Lucas C, DeMaggio M. Factors involved in successful psychotherapy referral in rural primary care. Fam Med 1991;23: 527-30.

82. Blount A. Integrated primary care: the future of medical and mental health collaboration. New York (NY): W.W. Norton \& Company; 1998.

83. Griswold KS, Greene B, Smith SJ, Behrens T, Blondell RD. Linkage to primary medical care following inpatient detoxification. Am J Addict 2007; 16:183-6.

84. Griswold KS, Servoss TJ, Leonard KE, et al. Connections to primary medical care after psychiatric crisis. J Am Board Fam Pract 2005;18:166-72.

85. Bartter T, Pratter MR. Asthma: better outcome at lower cost? The role of the expert in the care system. Chest 1996;110:1589-96.

86. Hirth RA, Fendrick AM, Chernew ME. Specialist and generalist physicians' adoption of antibiotic therapy to eradicate Helicobacter pylori infection. Med Care 1996;34:1199-204.

87. Harrold LR, Field TS, Gurwitz JH. Knowledge, patterns of care, and outcomes of care for generalists and specialists. J Gen Intern Med 1999;14:499_ 511.

88. Hartz A, James PA. A systematic review of studies comparing myocardial infarction mortality for generalists and specialists: lessons for research and health policy. J Am Board Fam Med 2006;19:291302.

89. Kravitz RL, Duan N, Braslow J. Evidence-based medicine, heterogeneity of treatment effects, and the trouble with averages. Milbank Q 2004;82:66187.

90. Rothwell PM. External validity of randomised controlled trials: "to whom do the results of this trial apply?" Lancet 2005;365:82-93.

91. James PA, Cowan TM, Graham RP, Majeroni BA, Fox CH, Jaen CR. Using a clinical practice guideline to measure physician practice: translating a guideline for the management of heart failure. J Am Board Fam Pract 1997;10:206-12.

92. Donohoe MT. Comparing generalist and specialty care: discrepancies, deficiencies, and excesses. Arch Intern Med 1998;158:1596-608.

93. Grumbach K, Selby JV, Schmittdiel JA, Quesenberry CP Jr. Quality of primary care practice in a large HMO according to physician specialty. Health Serv Res 1999;34:485-502.

94. Bindman AB, Grumbach K, Osmond D, Vranizan K, Stewart AL. Primary care and receipt of preventive services. J Gen Intern Med 1996;11:269-76.

95. Villalbi JR, Guarga A, Pasarin MI, et al. [An evaluation of the impact of primary care reform on health]. Aten Primaria 1999;24:468-74.

96. Berwick DM. Public performance reports and the will for change. JAMA 2002;288:1523-4.

97. Wisconsin Collaborative for Healthcare Quality. Wisconsin Collaborative for Healthcare Quality [Homepage]. Available from www.wchq.org. Accessed 7 May 2008.

98. Nutting PA, Goodwin MA, Flocke SA, Zyzanski SJ, Stange KC. Continuity of primary care: to whom 
does it matter and when? Ann Fam Med 2003;1: $149-55$.

99. Singh R, Singh A, Taylor JS, Rosenthal TC, Singh $\mathrm{S}$, Singh G. Building learning practices with selfempowered teams for improving patient safety. J Health Management 2006;8:91-118.

100. Brooks RG, Menachemi N. Physicians' use of email with patients: factors influencing electronic communication and adherence to best practices. J Med Internet Res 2006;8:e2.

101. Kaushal R, Blumenthal D, Poon EG, et al. The costs of a national health information network. Ann Intern Med 2005;143:165-73.

102. Crosson JC, Stroebel C, Scott JG, Stello B, Crabtree BF. Implementing an electronic medical record in a family medicine practice: communication, decision making, and conflict. Ann Fam Med 2005;3:307-11.

103. O'Connor PJ, Crain AL, Rush WA, Sperl-Hillen JM, Gutenkauf JJ, Duncan JE. Impact of an electronic medical record on diabetes quality of care. Ann Fam Med 2005;3:300-6.

104. Mehrotra A, Epstein AM, Rosenthal MB. Do integrated medical groups provide higher-quality medical care than individual practice associations? Ann Intern Med 2006;145:826-33.

105. Campbell S, Reeves D, Kontopantelis E, Middleton E, Sibbald B, Roland M. Quality of primary care in England with the introduction of pay for performance. N Engl J Med 2007;357:181-90.

106. Parente DH, Pinto MB, Barber JC. A pre-post comparison of service operational efficiency and patient satisfaction under open access scheduling. Health Care Manage Rev 2005;30:220-8.

107. O'Connor ME, Matthews BS, Gao D. Effect of open access scheduling on missed appointments, immunizations, and continuity of care for infant well-child care visits. Arch Pediatr Adolesc Med 2006;160:889-93.

108. Kopach R, DeLaurentis PC, Lawley M, et al. Effects of clinical characteristics on successful open access scheduling. Health Care Manag Sci 2007;10: 111-24

109. Eads M. Virtual office visits: a reachable and reimbursable innovation. Fam Pract Manag 2007;14: 20-2.

110. Medfusion, Inc. Medfusion [Homepage] Available from http://www.medfusion.net. Accessed 26 December 2007.

111. Backer L. The medical home: an idea whose time has come.again. Fam Pract Manag 2007;14:38-41.

112. NC Foundation for Advanced Health Programs, Inc. Community Care of North Carolina. Program overview. Available from http://www.communitycarenc.com/. Accessed 1 May 2008.

113. Arvantes J. Support for medical home to be focus of upcoming bill. AAFP NewsNow. September 9, 2007.
114. Rosenthal TC, Horwitz ME, Snyder G, O'Connor J. Medicaid primary care services in New York state: partial capitation vs full capitation. J Fam Practice 1996;42:362-8.

115. Moran DW. Whence and whither health insurance? A revisionist history. Health Aff (Millwood) 2005;24:1415-25.

116. Enthoven AC. Consumer-choice health plan (second of two parts). A national-health-insurance proposal based on regulated competition in the private sector. N Engl J Med 1978;298:709-20.

117. Enthoven AC, van de Ven WP. Going Dutchmanaged-competition health insurance in The Netherlands. N Engl J Med 2007;357:2421-3.

118. Knottnerus JA, ten Velden GH. Dutch doctors and their patients-effects of health care reform in The Netherlands. N Engl J Med 2007;357:2424-6.

119. Campbell S, Steiner A, Robison J, et al. Do personal medical services contracts improve quality of care? A multi-method evaluation. J Health Serv Res Policy 2005;10:31-9.

120. Pollock AM, Price D, Viebrock E, Miller E, Watt G. The market in primary care. BMJ 2007;335: 475-7.

121. Crabtree BF, Miller WL, Aita VA, Flocke SA, Stange KC. Primary care practice organization and preventive services delivery: a qualitative analysis. J Fam Pract 1998;46:403-9.

122. Valderas JM, Kotzeva A, Espallargues M, et al. The impact of measuring patient-reported outcomes in clinical practice: a systematic review of the literature. Qual Life Res 2008;17:179-93.

123. Aitken JF, Janda M, Elwood M, Youl PH, Ring IT, Lowe JB. Clinical outcomes from skin screening clinics within a community-based melanoma screening program. J Am Acad Dermato. 2006;54: 105-14.

124. Fraguas R Jr, Henriques SG Jr, De Lucia MS, et al. The detection of depression in medical setting: a study with PRIME-MD. J Affect Disord 2006;91: 11-7.

125. Rodriguez GL, Ma F, Federman DG, et al. Predictors of skin cancer screening practice and attitudes in primary care. J Am Acad Dermatol 2007;57:77581.

126. Gawande A. Complications: a surgeon's notes on an imperfect science. New York (NY): Picador USA; 2003.

127. American Medical Association. RVS Update Committee (RUC). Available from http://www.amaassn.org/ama/pub/category/16401.html. Accessed 4 December 2007.

128. Goodson JD. Unintended consequences of resource-based relative value scale reimbursement. JAMA 2007;298:2308-10.

129. Bodenheimer T, Berenson RA, Rudolf P. The primary care-specialty income gap: why it matters. Ann Intern Med 2007;146:301-6. 
130. Ginsburg PB, Berenson RA. Revising Medicare's physician fee schedule-much activity, little change. N Engl J Med 2007;356:1201-3.

131. Gottschalk A, Flocke SA. Time spent in face-toface patient care and work outside the examination room. Ann Fam Med 2005;3:488-93.

132. Landon BE, Schneider EC, Normand ST. Quality of care in Medicaid managed care and commercial health plans. JAMA 2007;298:1674-81.

133. Reports C. Treatment traps to avoid: insured? You're money in the bank to the health care system. Consumer Reports 2007;72:12-7.

134. Mahar M. Money-driven medicine: the real reason health care costs so much. New York (NY): HarperCollins Publishers; 2006.

135. Mark DH, Gottlieb MS, Zellner BB, Chetty VK, Midtling JE. Medicare costs in urban areas and the supply of primary care physicians. J Fam Pract 1996;43:33-9.

136. Basu J, Clancy C. Racial disparity, primary care, and specialty referral. Health Serv Res 2001;36(6 Pt 2):64-77.

137. Whittle J, Lin CJ, Lave JR, et al. Relationship of provider characteristics to outcomes, process, and costs of care for community-acquired pneumonia. Med Care 1998;36:977-87.

138. National Association of Community Health Centers. [Homepage.] Available from www.nachc.com. Accessed 28 September 2007.

139. Dartmouth Atlas of Health Care. Performance report for chronically ill beneficiaries in traditional Medicare. Available from http://www.dartmouthatlas.org/data/download/perf_reports/STATE_perf_report.pdf. Accessed 18 December 2007.

140. Bridges to Excellence. Diabetes care analysis-savings estimate. Available from http://www.bridgestoexcellence.org. Accessed 2 August 2008.
141. Casalino LP, Devers KJ, Lake TK, Reed M, Stoddard JJ. Benefits of and barriers to large medical group practice in the United States. Arch Intern Med 2003;163:1958-64.

142. Pham HH, Ginsburg PB, McKenzie K, Milstein A. Redesigning care delivery in response to a highperformance network: the Virginia Mason Medical Center. Health Aff (Millwood) 2007;26:w532-44.

143. Davis K. Paying for care episodes and care coordination. N Engl J Med 2007;356:1166-8.

144. McDonald R, Harrison S, Checkland K, Campbell $\mathrm{SM}$, Roland M. Impact of financial incentives on clinical autonomy and internal motivation in primary care: ethnographic study. BMJ 2007;334:1357.

145. Pawlson LG, Scholle SH, Powers A. Comparison of administrative-only versus administrative plus chart review data for reporting HEDIS hybrid measures. Am J Manag Care 2007;13:553-8.

146. Snyder L, Neubauer RL. Pay-for-performance principles that promote patient-centered care: an ethics manifesto. Ann Intern Med 2007;147:792-4.

147. Dunbar L, Hiza D, Hoffman J, et al. Outcomesbased compensation: performance design principles. Paper presented at 4th Annual Disease Management Outcomes Summit, Rancho Mirage, California, 2004.

148. Gilmore AS, Zhao Y, Kang N, et al. Patient outcomes and evidence-based medicine in a preferred provider organization setting: a six-year evaluation of a physician pay-for-performance program. Health Serv Res 2007;42(6 Part 1):2140-59.

149. Campbell SM, McDonald R, Lester H. The experience of pay for performance in English family practice: a qualitative study. Ann Fam Med 2008;6: 228-34.

150. National Institute for Health and Clinical Excellence. [Homepage.] Available from www.nice. org.uk. Accessed 2 August 2008. 